\title{
Análise do desgaste de capas de eletrodos de solda ponto e sua influência na qualidade da soldagem de chapas automotivas galvanizadas
}

\section{(Assessment of spot welding electrodes wearing and their influence on the quality of welded automotive galvanized sheets)}

\author{
Hideraldo Luiz Osório Branco ${ }^{1}$, Paulo Cesar Okimoto ${ }^{2}$ \\ ${ }^{1}$ Tecnowelding Ind. e Com. Ltda, Curitiba, PR, Brasil, tecnowelding@tecnowelding.ind.br \\ ${ }^{2}$ Universidade Federal do Paraná, Departamento de Engenharia Mecânica, Setor de Tecnologia, Curitiba, PR, Brasil, okimoto@, \\ ufpr.br
}

\section{Resumo}

As capas de eletrodos utilizados na soldagem por resistência por pontos (solda ponto) sofrem desgaste durante a soldagem de chapas galvanizadas, devido a elevado aquecimento e pressão na sua superfície. Neste trabalho avaliou-se a influência do desgaste sofrido por diferentes tipos de capas de eletrodos sobre as propriedades mecânicas e acabamento do ponto de solda. Observou-se que o desgaste varia de acordo com a capacidade de retenção de dureza a quente, e que a superficie das capas sofre intensa reação com o zinco da chapa galvanizada. Como conseqüencia do desgaste das capas de eletrodo, o ponto de solda sofre redução progressiva do seu diâmetro (o que pode comprometer sua integridade estrutural), além de uma piora significativa do seu acabamento superficial.

Palavras-chave: Solda ponto, chapas galvanizadas, desgaste.

\begin{abstract}
Electrodes caps used in RSW wear out during the welding of galvanized sheets, caused by the high heating and pressure. In this work was evaluated the wearing influence of different kinds of electrodes caps over mechanical properties and surface finish of the spot weld. Was also observed that the wearing varies according to the hot hardness retention capacity, and the electrode caps surface suffer an intense reaction with zinc from the galvanized sheet. As a result of the electrodes caps wearing, the spot weld diameter is progressively reduced, that can compromise it's structural integrity.
\end{abstract}

Key-words: Spot welding, galvanized sheets, wear.

\section{Introdução}

A soldagem por resistência por pontos - RSW, comumente denominada de solda ponto, é amplamente utilizada na união de chapas de aço galvanizadas. Uma das principais aplicações da solda ponto é na fabricação de carrocerias automotivas de aço, que contêm em média 4.500 pontos de solda. A integridade estrutural dos pontos de solda é, portanto, essencial para garantir que as carrocerias automotivas suportem os requisitos do crash test e sejam considerados seguros $[1,2,3]$.

Os eletrodos utilizados na soldagem por resistência desempenham um papel fundamental para obter soldas de qualidade, pois são responsáveis por transferir para as peças a corrente e a pressão necessária para a geração de aquecimento por efeito joule, além de dissipar o calor gerado para possibilitar uma rápida solidificação da zona fundida. De maneira geral, considerando as diferentes aplicações, a corrente de soldagem

(Recebido em 20/03/2012; Texto final em 30/07/2012). varia entre 5 a $20 \mathrm{kA}$, a força aplicada entre 1,5 a $8 \mathrm{kN}$, sendo que a temperatura na superfície de contato do eletrodo / chapa pode atingir até $900^{\circ} \mathrm{C}[4,5,6]$. Podem apresentar vários formatos, tais como capas, pontas arredondadas, discos, rolos, dependendo da configuração da peça a ser soldada.

$\mathrm{Na}$ fabricação de carrocerias automotivas normalmente se utilizam eletrodos na forma de capas, denominadas capas de eletrodo (daqui por diante será utilizado o termo simplificado de capa apenas). Estas capas trabalham sob condições muito severas, pois as soldas são executadas em alta velocidade, normalmente com o uso de robôs industriais. Esta condição de trabalho, mais o aquecimento sofrido pelas capas e a pressão que as mesmas exercem sobre as chapas durante a soldagem resultam num desgaste significativo ao longo da execução de um grande número de pontos de solda.

Guedes ETAL [7] avaliaram o desgaste dos eletrodos sofridos durante a soldagem de chapas galvanizadas, e sua influência sobre a corrente de soldagem . Observaram que a corrente de soldagem cai progressivamente com o aumento do número de pontos soldados, devido a formação de uma camada rica em Zn e de elevada dureza na superfície dos eletrodos. A redução da corrente de soldagem acarreta uma redução do efeito joule significativa, pois o mesmo varia com o quadrado da corrente. 
Este fato tende a reduzir o tamanho da zona fundida do ponto de solda, o que pode comprometer a sua integridade estrutural. Fukumoto ET AL [8] analisaram a influência do desgaste das capas na soldagem de chapas de alumínio. Concluíram que o desgaste sofrido pela capa acarreta redução progressiva do diâmetro do ponto de solda, uma vez que há uma redução da densidade de corrente na região a ser soldada, em conseqüência do aumento do diâmetro da face da capa.

Considerando as capas atualmente utilizadas na soldagem de chapas galvanizadas, nota-se que há poucas informações disponíveis sobre o desgaste das mesmas. Na literatura divulgada pelos fabricantes de capas, existem informações de cunho comercial, entretanto as dados sobre desgaste são vagas e pouco precisas. Muitos livros na área de soldagem [2, 9, 10, 11] trazem informações sobre alguns tipos de capas, porém as mesmas são desatualizadas, pois consideram apenas capas de ligas mais antigas.

Há, portanto, uma falta de informações sobre os fatores que relacionam o desgaste das capas com a qualidade do ponto de solda obtido, o que impede um melhor planejamento da soldagem quando se executam milhares de pontos. $\mathrm{O}$ presente trabalho visa estudar o desgaste em diferentes tipos de capas atualmente utilizadas pela indústria automotiva na soldagem de chapas galvanizadas, e verificar sua influência sobre as propriedades mecânicas e o acabamento do ponto de solda obtido.

\section{Materiais e Métodos}

\subsection{Chapas e capas de eletrodos}

Os pontos de solda foram realizados utilizando duas chapas galvanizadas com dimensões de $50 \times 200 \mathrm{~mm}$, conforme mostra do na Figura 1. A primeira chapa tem a especificação XES G 10/10 (Normas Renault 11-00-214/C; 11-04-805/E; 02-30402/-C e 32-00-019/--B), com espessura da chapa $0,67 \mathrm{~mm} \mathrm{e}$ revestimento mínimo de $\mathrm{Zn}$ de $10,0 \mu \mathrm{m}$, processo de revestimento por imersão. A segunda chapa tem a especificação st06 G 10/10 (Normas DIN EN 10413; VW50111 e ST06Z100MB) com espessura da chapa $1,0 \mathrm{~mm}$ e revestimento de $\mathrm{Zn}$ de 6 a $12 \mu \mathrm{m}$, processo de revestimento por imersão. Para a realização dos pontos de solda, as chapas foram sobrepostas, sendo que a chapa superior foi a chapa com espessura de $0,67 \mathrm{~mm}$. Em cada chapa de trabalho foram executados 39 pontos de solda, distantes de centro a centro de $15 \mathrm{~mm}$.

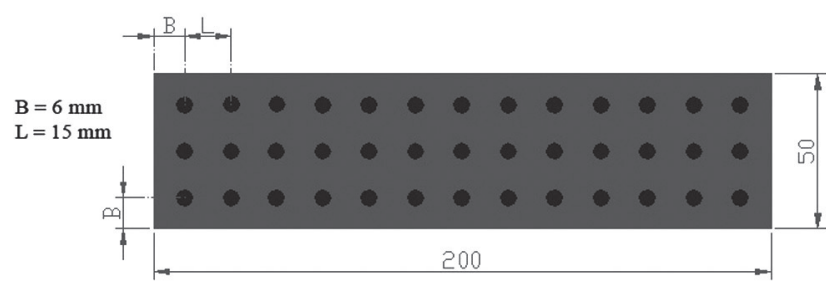

Figura 1. Dimensões da área de trabalho.

Foram utilizados 4 tipos de capas especificadas na Tabela
01. As capas A, B e C são endurecidas por precipitação, classificadas como RWMA classe 1 [12]. Apesar de possuírem a mesma composição química, as capas $\mathrm{A}$ e $\mathrm{C}$ diferenciamse pelo fato da capa $\mathrm{C}$ ser livre do oxigênio. A capa $\mathrm{D}$ é um compósito endurecido por dispersão, classificada como RWMA classe 20 [12]. O endurecimento é realizado pela utilização de partículas de $\mathrm{Al}_{2} \mathrm{O}_{3}$ de dimensões entre 3 a $12 \mathrm{~nm}$, espaçadas de 30 a $10 \mathrm{~nm}$. Tal microestrutura é obtida durante o processo de fabricação, que utiliza uma liga fundida de $\mathrm{Cu}-\mathrm{Al}$, seguido de pulverização e oxidação seletiva do alumínio, formando o $\mathrm{Al}_{2} \mathrm{O}_{3}$ numa densidade de $10^{16}-10^{17}$ partículas $/ \mathrm{cm}^{3}$ [13]. Todas as capas utilizadas são do tipo cone truncado, fêmeas com cone interno 1:10, diâmetro da face de $6 \mathrm{~mm}$, altura de $20 \mathrm{~mm}$, diâmetro do corpo de $16 \mathrm{~mm}$ e uma inclinação de $30^{\circ}$ como indicado na Figura 2.

Tabela1. Composição química das capas utilizadas nos testes.

\begin{tabular}{|c|l|l|l|}
\hline Capa & Composição & \multicolumn{1}{|c|}{$\%$ Elementos } & Processo Fabricação \\
\hline A & $\mathrm{CuZr}$ & $0.15-0.20 \% \mathrm{Zr}$ & Estampado a Frio \\
\hline $\mathrm{B}$ & $\mathrm{CuCrZr}$ & $1 \% \mathrm{Cr} ; 0,25 \% \mathrm{Zr}$ & Usinado \\
\hline $\mathrm{C}$ & $\mathrm{CuZr}(\mathrm{OF})$ & $0.15-0.20 \% \mathrm{Zr}$ & Estampado a Frio \\
\hline $\mathrm{D}$ & $\mathrm{CuAl} \mathrm{O}_{3}$ & $1.1 \% \mathrm{Al}_{2} \mathrm{O}_{3}$ & Estampado a Frio \\
\hline
\end{tabular}

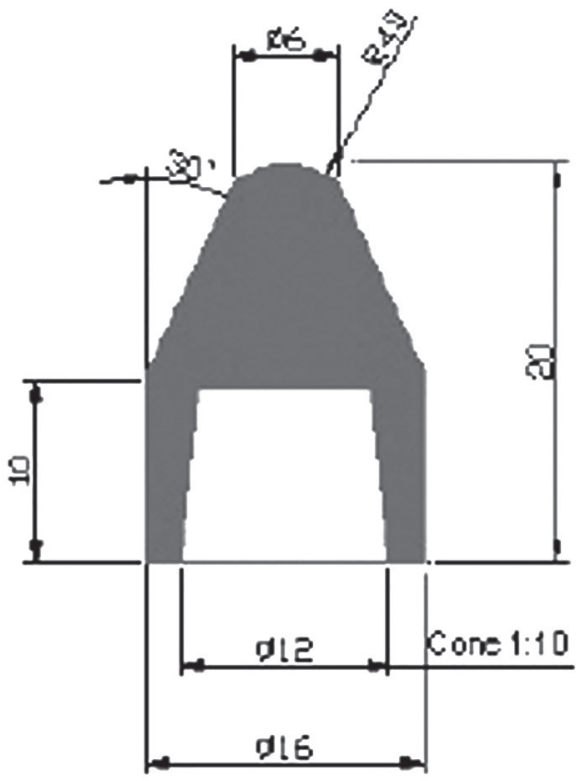

Figura 2. Desenho das capas utilizadas.

\subsection{Máquina de Solda}

Os pontos de solda foram realizados em uma máquina de solda a ponto estacionária marca Siegel de $20 \mathrm{KVA}$, refrigerada a água, 5 taps de regulagem da potência da máquina, corrente alternada, com acionamento pneumático por pedal. Este equipamento foi calibrado para garantir os parâmetros de soldagem utilizados. O tempo e corrente de soldagem foram calibrados com medidor de corrente Miyachi MM-315A com toróide, e range de corrente 
de 1,00 - 49,9 kA, e a medição de pressão foi calibrada com um dinamômetro digital Miyachi MM-601 A, com célula de carga e range de $20-950 \mathrm{~kg}$.

\subsection{Determinação do Diâmetro médio do Ponto de Solda}

A integridade estrutural do ponto de solda foi medida através do teste de arrancamento, como mostrado na Figura 3a, em corpos de prova obtidos soldando-se pequenas chapas de $0.67 \times 16 \times 50 \mathrm{~mm}$ e $1.00 \times 16 \times 50 \mathrm{~mm}$, como mostrado na Figura 3b. O diâmetro médio do ponto de solda foi determinado pela equação 1, conforme mostrado nas Figuras $3 \mathrm{c}$ a $3 \mathrm{f}$.

$$
\mathrm{D}_{\text {médio }}=\left(\mathrm{D}_{\text {máx }}+\mathrm{D}_{\text {min }}\right) / 2
$$

Figura 3. Teste de arrancamento, corpos de prova e determinação do diâmetro médio do ponto de solda.

No caso da soldagem de chapas de diferentes espessuras, normas industriais [14] recomendam que o ponto de solda apresente um diâmetro mínimo, calculado pela expressão 2 , onde $\mathrm{D}_{\text {ponto }}$ é o diâmetro mínimo do ponto de solda e $\mathrm{S}$ é a espessura da chapa mais fina a ser soldada. Assim, para este estudo, será utilizado $\mathrm{D}_{\text {ponto }}=3,44 \mathrm{~mm}$.

$\mathrm{D}_{\text {ponto }}=4,2 \times \mathrm{S}^{1 / 2}$

\subsection{Parâmetros de Soldagem}

Os parâmetros de soldagem foram escolhidos de forma a atender o critério do $\mathrm{D}_{\text {ponto }}$, além de evitar defeitos como ponto deslocado, indentação excessiva, queima da superfície da chapa, fusão da superfície e grudamento das capas na superfície da chapa. Foram definidos os seguintes parâmetros de soldagem:

- Corrente de soldagem: 6,00 kA.

- Tempo de soldagem: $400 \mathrm{~ms}$.

- Força entre as capas de eletrodos: $56 \mathrm{kgf}$.

- Vazão total de água para refrigeração: $91 / \mathrm{min}$.

- Velocidade de soldagem: 40 pontos de solda por minuto.

\subsection{Testes de desempenho e desgaste das capas}

Nos testes de soldagem, para avaliar a produtividade e o desgaste das capas, foram realizados testes de arrancamento a cada 100 pontos de solda e medido o $\mathrm{D}_{\text {médio }}$ conforme procedimento descrito no item 2.3., até que fosse atingido um valor inferior ou próximo do $\mathrm{D}_{\text {ponto }}$ de $3,44 \mathrm{~mm}$.

Para verificar como as capas eram degradadas ao longo das soldagens realizadas, as faces das capas foram fotografadas em microscópio estereoscópio no mesmo intervalo de 100 pontos de solda. Foram ainda controlados o diâmetro da face da capa, utilizando-se esse resultado como medida de desgaste.

\subsection{Testes de Recozimento Isotérmico}

Análises térmicas realizadas por Yeung e Thornton [6] mostraram que as regiões próximas da região de contato da face da capa com a chapa atingem temperaturas entre 700 a $900^{\circ} \mathrm{C}$. Visando verificar como a dureza das capas variam em função do aquecimento, as mesmas foram recozidas isotermicamente a $700^{\circ} \mathrm{C}, 800^{\circ} \mathrm{C}$ e $900^{\circ} \mathrm{C}$, por um período de 10 minutos em cada temperatura, seguindo-se medida de dureza em um microdurômetro Tukon, modelo MO, com indentador Vickers, e uma carga de 200 gramas.

\subsection{Ensaio de microdureza}

Ensaios de microdureza foram executados em capas que foram submetidos a soldagem de 600 pontos de solda, com fresagem da face das capas a cada 120 pontos, com o mesmo equipamento utilizado para as amostras que fora recozidas isotermicamente. Em cada fresagem foi retirado $0,15 \mathrm{~mm}$ de material na face da capa para que ficasse isento de crateras e sem a camada de latão, mantendo também o diâmetro de $6 \mathrm{~mm}$ nesta face. A forma de fresagem utilizada para recuperar o perfil da capa de eletrodo foi a fresagem de topo e lateral.

As medidas de microdureza foram realizadas conforme mostrado na figura 4 , com três perfis de dureza ao longo da seção transversal da capa, distância entre perfis de $2,0 \mathrm{~mm}$ e a distância entre indentações de $150 \mu \mathrm{m}$. A primeira indentação foi efetuada na camada de latão formada na face da capa.

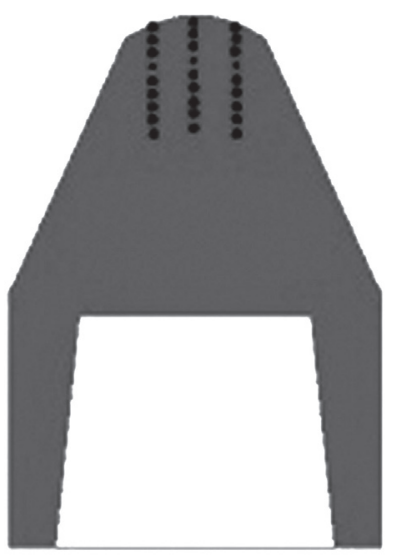

Figura 4. Esquema para mediação do perfil de microdureza das capas após a realização de 600 pontos de solda, com fresagem de $0,15 \mathrm{~mm}$ a cada 120 pontos.

\subsection{Análise metalográfica e microscopia eletrônica de varredura}

As capas A, B, C e D utilizadas nos testes de desgate e os pontos de solda obtidos foram preparados para análise metalográfica na seção transversal, através de embutimento a quente em baquelite, seguido de lixamento com lixas de grana $180,320,400,600$ e 1200 , e polimento com alumina de $1 \mu \mathrm{m}$. Para os pontos de solda utilizou-se um ataque químico em solução de $60 \mathrm{ml}$ de ácido nítrico (pureza 65\%) e $140 \mathrm{ml}$ de água destilada, por cerca de 5 segundos. A análise metalográfica foi 


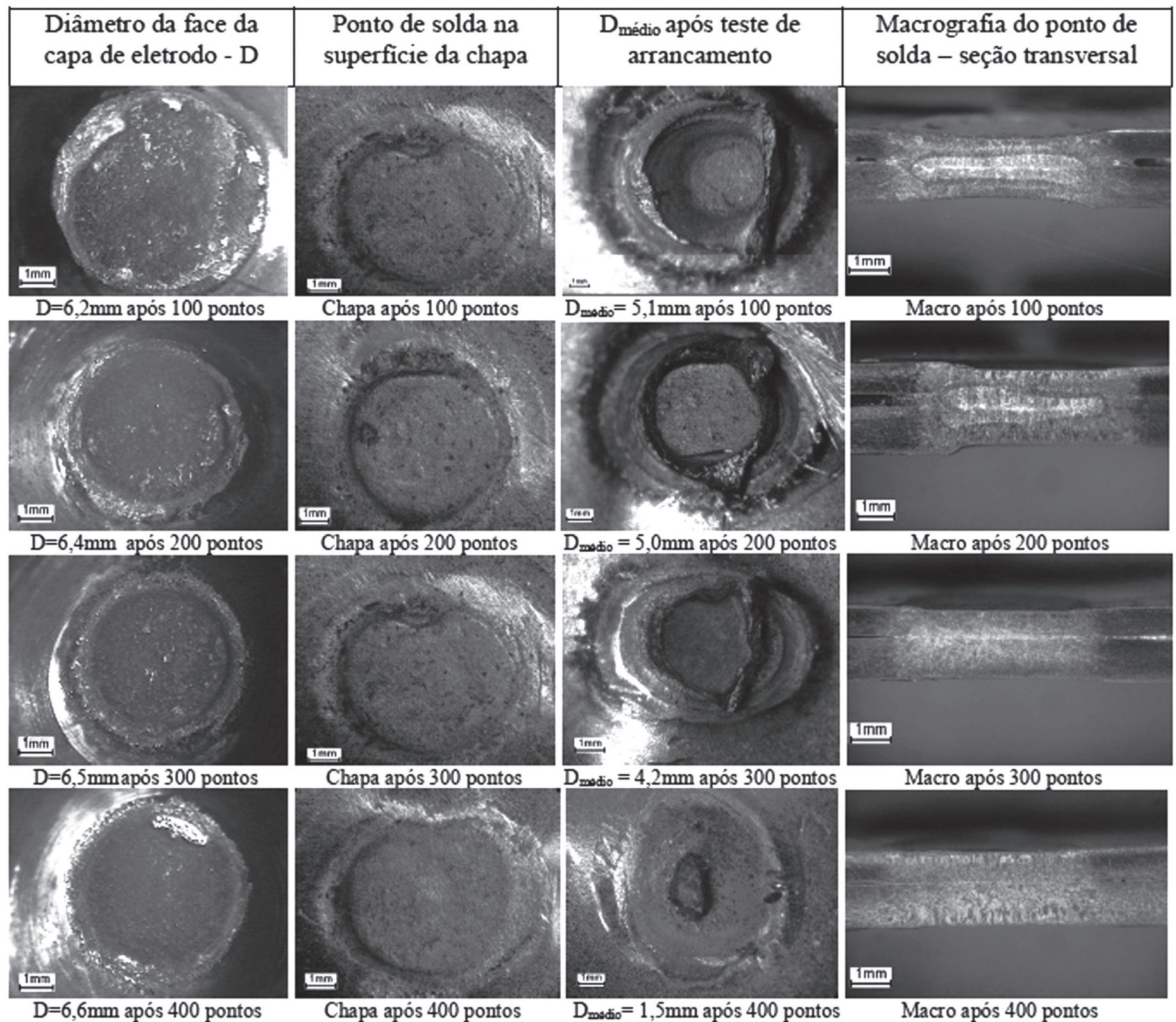

Figura 5. Variação das características da face da capa A e dos pontos de solda realizados com a mesma capa, em função do número de pontos executados.

realizada em microscópio Olympus BX-51, visando caracterizar a microestrutura ao longo da seção transversal das capas.

Foi utilizado um microscópio eletrônico de varredura (MEV), marca Philips, modelo XL 30, para observar a camada de latão formada na face da capa e realizar análises semi-quantitativa da composição química destas camadas, empregando-se a técnica de espectroscopia por dispersão de energia (EDS - Energy Dispersion Spectroscopy).

\section{Resultados e Discussão}

\subsection{Testes de soldagem}

Nas figuras 5 e 6 são mostradas as modificações observadas na face das capas A e D respectivamente em função do número de pontos de solda executados, assim como as características do ponto de solda na superfície da chapa de aço galvanizada, do $\mathrm{D}_{\text {médio }}$ após o teste de arrancamento e da macrografia do ponto de solda na seção transversal. Para ambos os casos, nota-se que ocorrem intensas modificações a medida que os pontos de solda executados aumentam. A primeira modificação é observada no diâmetro da face das capas que entram em contato com a chapa galvanizada durante a soldagem, que aumentam gradativamente. Esta variação é decorrência da deformação plástica sofrida pela capa, devido ao aquecimento localizado nesta região e da pressão exercida durante as soldagens realizadas. Trata-se, portanto, de uma forma de desgaste que ocorre continuamente e se acentua de 

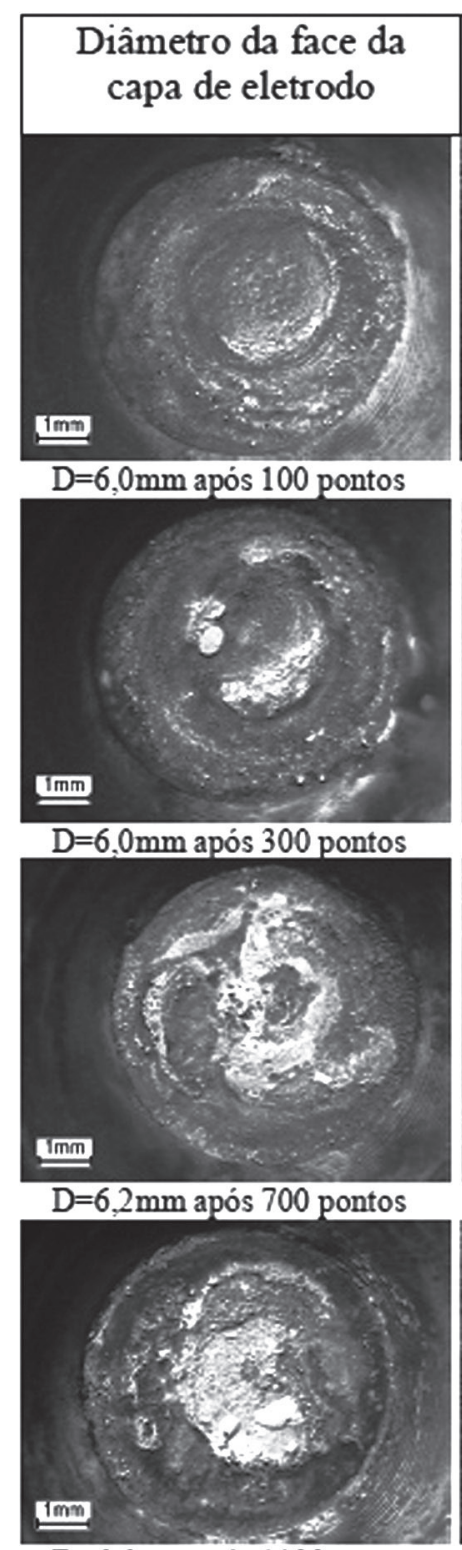

$\mathrm{D}=6,6 \mathrm{~mm}$ após 1100 pontos

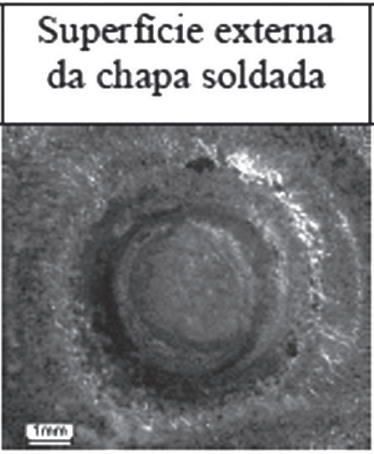

Chapa após 100 pontos

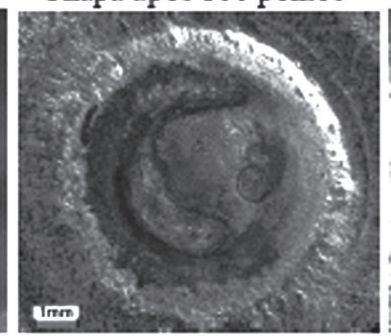

Chapa após 300 pontos

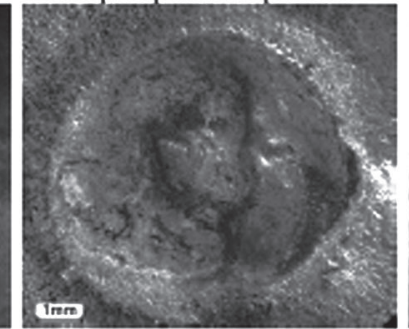

Chapa após 700 pontos

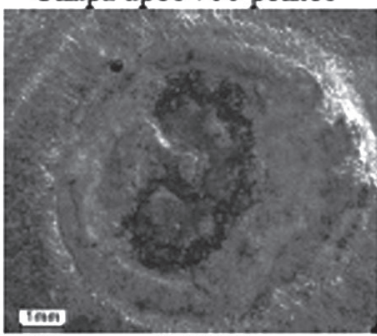

Chapa após 1100 pontos
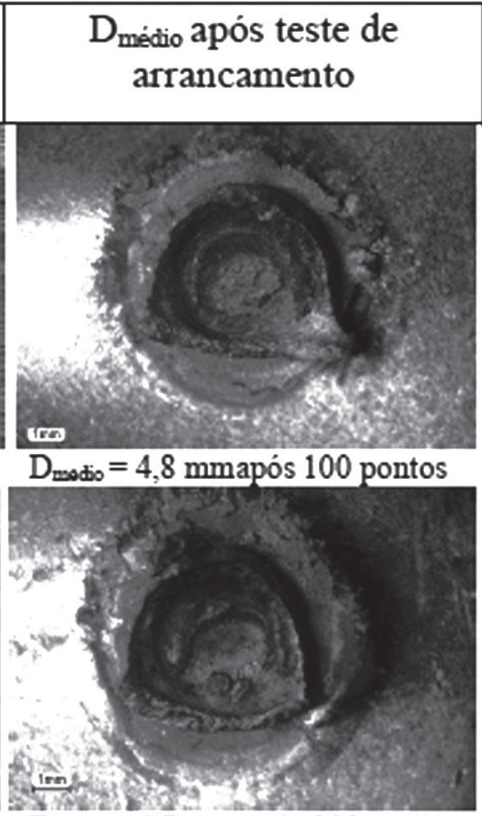

$\mathrm{D}_{\mathrm{motio}}=4.7 \mathrm{~mm}$ após 300 pontos

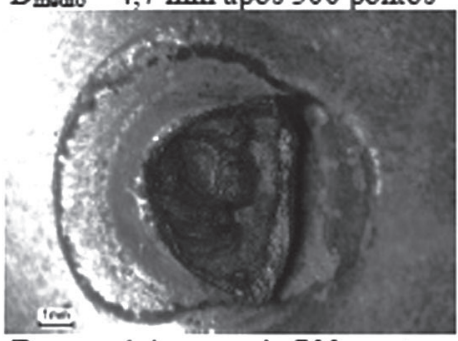

$\mathrm{D}_{\text {mesio }}=4,4 \mathrm{~mm}$ após 700 pontos

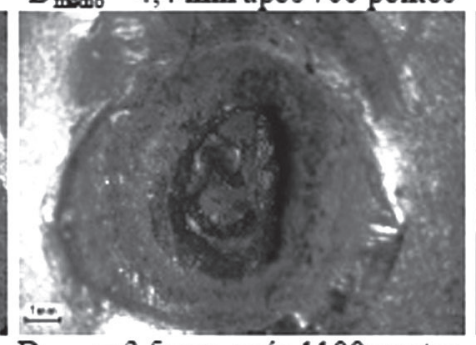

$\mathrm{D}_{\text {moxa }}=3,5 \mathrm{~mm}$ após 1100 pontos

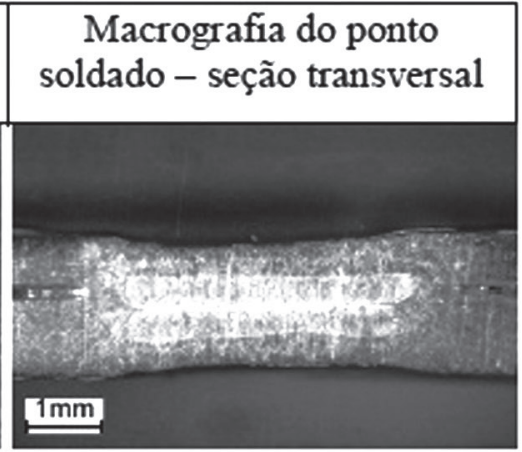

Macro 100 pontos

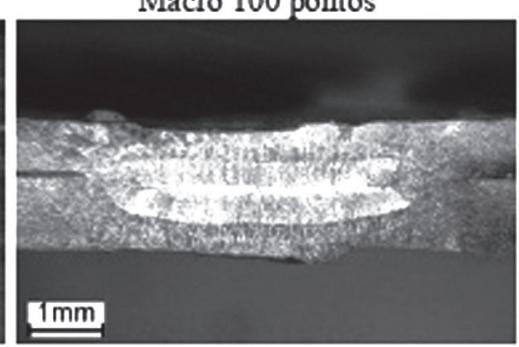

Macro 300 pontos

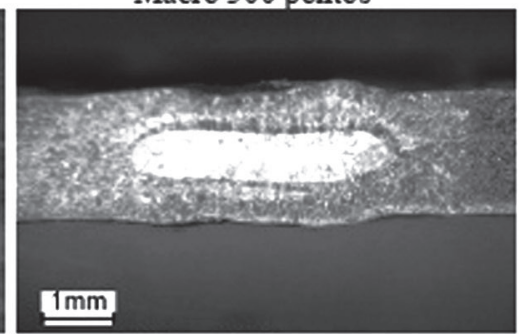

Macro 700 pontos

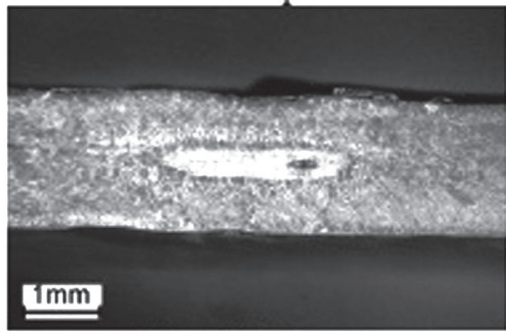

Macro 1100 pontos

Figura 6. Variação das características da face da capa $\mathrm{D}$ e dos pontos de solda realizados com a mesma capa, em função do número de pontos executados.

acordo com o número de pontos de solda executados pela capa. As capas B e C mostraram o mesmo comportamento.

Tomando-se como medida de desgaste a variação do diâmetro da face da capa, verificou-se que as capas apresentam desgaste bastante diferenciado, conforme mostrado na figura 7. As capas $\mathrm{D}$ e C apresentam os menores desgastes, com variação de apenas $0,6 \mathrm{~mm} / 1100$ pontos e $0,6 \mathrm{~mm} / 800$ pontos respectivamente. Os piores resultados foram para as capas B e A, com $0,9 \mathrm{~mm} /$ 600 pontos e $0,6 \mathrm{~mm} / 400$ pontos respectivamente.

A face da capa sofre ainda outros danos, que é mais perceptível na figura 6 . A partir de 300 pontos de solda executados começam a surgir as crateras, que aparecem como ilhas na superfície da capa. A extensão das crateras aumenta rapidamente a partir de seu aparecimento, atingindo uma extensão relativamente grande da área de contato, à medida que o número de pontos de solda aumenta progressivamente. O aumento das crateras foi estudado por Dong ET AL [15], e é influenciada por uma alta distribuição de densidade de corrente na borda da cratera a partir do seu aparecimento. Fukumoto ET AL [8] observou que a formação de pequenas crateras inicialmente ocorre próximo da periferia da face de contato da capa de eletrodo, e aumentam de profundidade e o diâmetro, formando crateras maiores por combinarem com outras pequenas crateras.

A presença das crateras na face das capas faz com que as chapas soldadas com estas capas passem a deixar marcas no ponto de solda, com o formato igual ao das crateras. Isto afeta o acabamento do ponto, que passa a ter uma superfície irregular. Apesar disto, o teste de arrancamento mostrou que as regiões marcadas pelas crateras permanecem soldadas no ponto resultante, conforme pode ser visto na figura 6 . 
Fica ainda evidente, ao analisar as figuras 5 e 6 , que a medida que o desgaste da capa aumenta há redução do $\mathrm{D}_{\text {médio }}$ medido no teste de arrancamento. Este resultado é confirmado pelas macrografias dos pontos de solda na seção transversal, que mostra que a medida que o número de pontos executados aumenta, as indentações nas chapas vão diminuindo e com isso também vão diminuindo o tamanho da zona fundida dos pontos de solda, até chegar no limite de não ocorrer fusão ou o ponto estar abaixo do seu valor mínimo. Este resultado mostra a importância na manutenção periódica da geometria da capa de eletrodo, através de fresamento, para recuperação das suas dimensões originais.

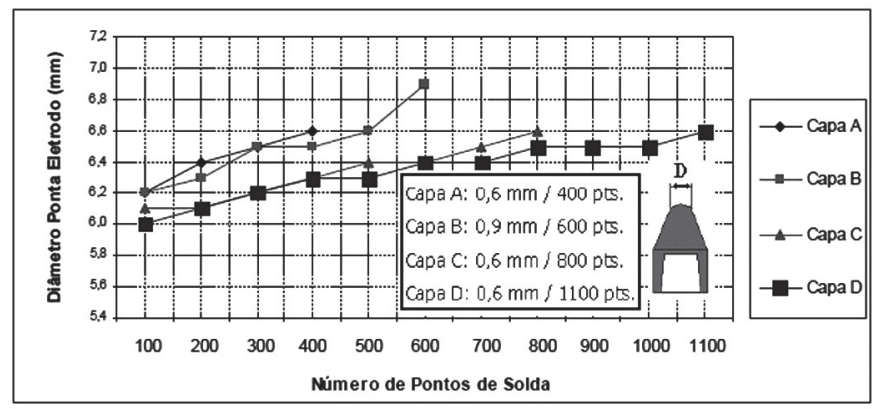

Figura 7. Variação do diâmetro da face da capa $x \mathrm{~N}^{0}$ pontos de pontos de solda executados.

A variação do $\mathrm{D}_{\text {médio }}$ medido após o teste de arrancamento é mostrado na figura 8 , em função do número de pontos de solda executados para os diferentes tipos de capas. No início dos testes o $\mathrm{D}_{\text {médio }}$ era aproximadamente $5 \mathrm{~mm}$ para todas as capas, mas no decorrer dos testes foram observadas diferenças consideráveis. Em todas as capas houve redução do $\mathrm{D}_{\text {médio }}$ porém a capa $\mathrm{D}$ mostrou-se significativamente superior às demais, tendo soldado 1100 pontos sem ter ainda atingido o $\mathrm{D}_{\text {ponto }}$ de $3,44 \mathrm{~mm}$. A capa $\mathrm{C}$ também apresentou bons resultados, tendo atingido 800 pontos. O pior resultado ocorreu com a capa $\mathrm{A}$ com 400 pontos e $\mathrm{D}_{\text {ponto }}$ abaixo do mínimo. Interessante notar que as capas $\mathrm{A}$ e $\mathrm{C}$ possuem a mesma composição química e o mesmo processo de fabricação, porém os resultados são muito diferentes quanto ao número de pontos atingido. A possível razão para esta diferença é que a capa $\mathrm{C}$ foi fabricada com o uso de cobre livre de oxigênio, o que favorece um menor desgaste, conforme mostrado na figura 7.

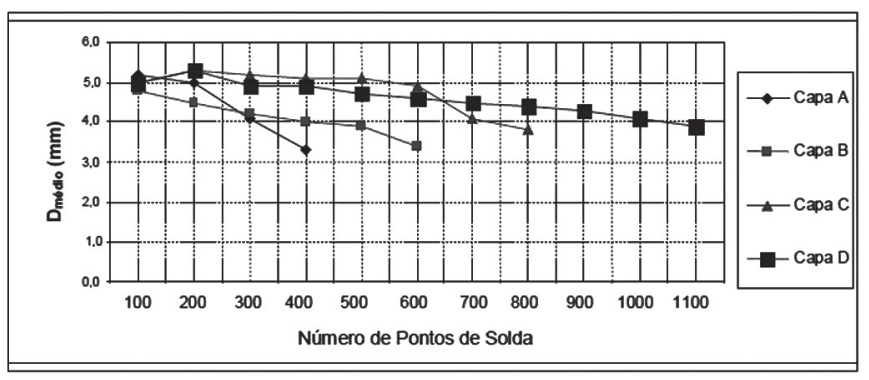

Figura 8. Variação do $\mathrm{D}_{\text {médio }}$ em função do número de pontos de solda executados.
Os resultados dos ensaios de recozimento isotérmico das capas mostrados na figura 9 ajudam a compreender o desgaste diferenciado observado. No estado como recebido, as capas apresentam dureza variando entre 118 a $180 \mathrm{HV}$, porém ao efetuar o recozimento isotérmico as durezas apresentam queda. A $700^{\circ} \mathrm{C}$, as capas $\mathrm{A}, \mathrm{B}$ e $\mathrm{C}$ apresentaram quedas de dureza variando entre 60 a $70 \mathrm{HV}$ em relação ao estado como recebido, e a $900^{\circ} \mathrm{C}$ estas 3 capas apresentam praticamente a mesma dureza, na faixa de $60 \mathrm{HV}$. Este resultado demonstra que o mecanismo de endurecimento por precipitação utilizado nestas ligas praticamente desaparece, por solubilização ou superenvelhecimento dos precipitados. Já a capa D apresenta uma queda de dureza de apenas $20 \mathrm{HV}$ em relação ao estado como recebido, variando de 180 para $160 \mathrm{HV}$ quando submetido a temperatura de $900^{\circ} \mathrm{C}$, demonstrando que o mecanismo de endurecimento por dispersão pouco é afetado pelo aquecimento da capa do eletrodo, uma vez que as partículas de $\mathrm{Al}_{2} \mathrm{O}_{3}$ são estáveis nesta faixa de temperatura.

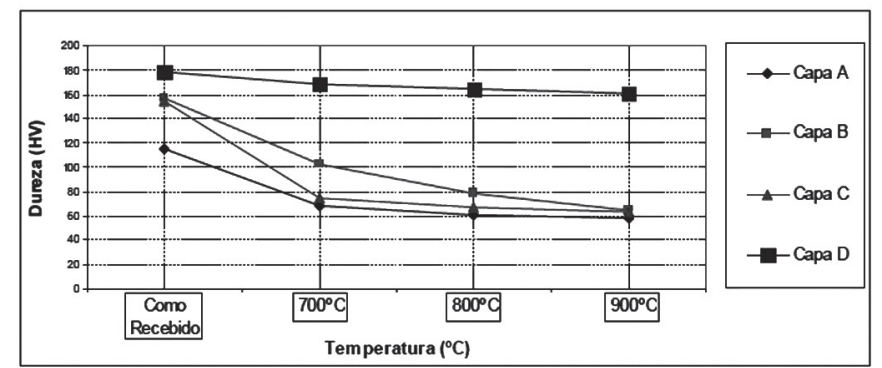

Figura 9. Medidas de dureza HV das capas em função da temperatura de recozimento isotérmico.

Ao analisar os dados conjuntos de dureza após o recozimento isotérmico e desgaste, nota-se que quanto menor a queda de dureza em função do aumento da temperatura, menor é o desgaste observado. Este resultado seria o esperado, pois o aquecimento da face da capa é acentuado e as deformações plásticas ocorrerão mais facilmente quanto menor for a dureza nesta região. Obviamente capacidade de reter a dureza em elevadas temperaturas tem um papel fundamental na produtividade das capas de eletrodo, por reduzir seu desgaste.

Para estimar a temperatura atingida na face das capas durante a soldagem, foram realizadas medidas de microdureza na seção transversal das 4 capas após a soldagem de 600 pontos, conforme mostrado na figura 10 . O procedimento para atingir estes 600 pontos incluiu fresagens intermediárias (usinagem da face da capa feita em torno para recuperar a parte desgastada de aproximadamente $0,15 \mathrm{~mm}$ ) a cada 120 pontos, pois junto a face da capa ocorre a formação de latão, devido a reação entre o cobre da capa e o zinco da chapa galvanizada, formando uma camada de difusão - $\mathrm{CD}$. Isto acarreta uma dureza muito elevada nesta camada, que atinge $231 \mathrm{HV}, 261 \mathrm{HV}, 297 \mathrm{HV}$ e $341 \mathrm{HV}$ para as capas A, B, C e D respectivamente. Abaixo desta camada, a dureza cai para todas as capas em relação ao estado como recebido. A capa A teve uma queda de dureza de $115 \mathrm{HV}$ para $61 \mathrm{HV}$, a capa B de $157 \mathrm{HV}$ para $83 \mathrm{HV}$, a capa C 
de $155 \mathrm{HV}$ para $70 \mathrm{HV}$ e a capa D de $178 \mathrm{HV}$ para $167 \mathrm{HV}$. Estes resultados mostram que a temperatura atingida na superfície das capas dos eletrodos está situada entre 800 e $900^{\circ} \mathrm{C}$ para todos as 4 diferentes capas, baseando-se tal afirmação nas durezas obtidas no testes de recozimento isotérmico.

A figura 10 ainda indica que a medida que se afasta da face da capa a dureza aumenta progressivamente. Para as capas A, $\mathrm{B}$ e $\mathrm{C}$ as durezas começam a se estabilizar a partir de $1,5 \mathrm{~mm}$ abaixo da camada de latão. Considerando que as fresagens são realizadas retirando-se 0,15 a $0,30 \mathrm{~mm}$ da face da capa, concluise que este procedimento é insuficiente para recuperar a dureza original das capas, que ficaram com durezas menores. A capa D apresentou um comportamento diferenciado, com uma queda de apenas $11 \mathrm{HV}$ em relação a sua dureza original, e praticamente mantendo esta dureza ao longo do perfil da capa. Tal resultado coincide com os observados nos tratamentos isotérmicos, onde a dureza se manteve mesmo com o aquecimento a $900^{\circ} \mathrm{C}$.

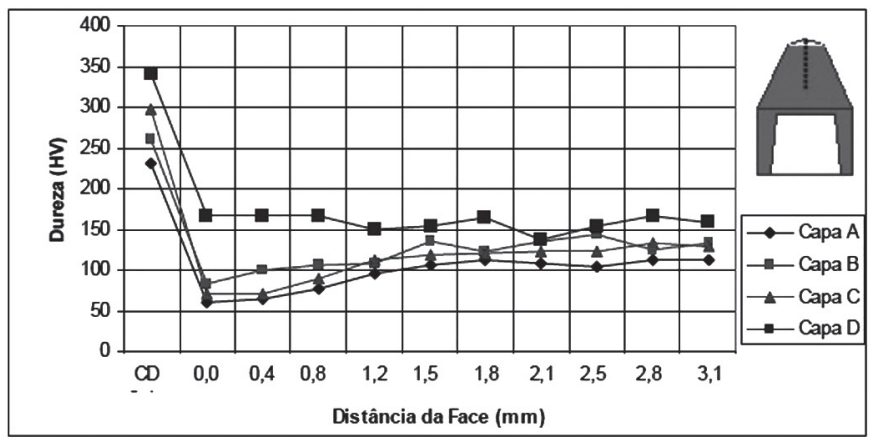

Figura 10. Perfil de dureza na seção transversal das capas de eletrodo após testes de soldagem.

Os resultados do $\mathrm{D}_{\text {médio }}$ e do diâmetro das faces das capas mostram uma relação entre desgaste e a quantidade de pontos soldados. À medida que a capa se desgasta, a densidade de corrente que passa pelo ponto de solda se reduz, devido ao aumento do diâmetro da face da capa. Esta redução de densidade de corrente implica em menor aquecimento por efeito joule, o que reduz o Dmédio. Estes resultados são consistentes com os obtidos por Fukumoto ET AL [8], e confirmam a importância do controle do desgaste para garantir que os pontos de solda atinjam um $\mathrm{D}_{\text {médio }}$ acima do $\mathrm{D}_{\text {ponto }}$.

Uma vez que o desgaste sofrido pelas capas depende de sua capacidade em reter a dureza em alta temperatura, pode-se concluir que este fator afeta diretamente o $\mathrm{D}_{\text {médio }}$ Quanto menor esta capacidade, maior o desgaste, menor será o $\mathrm{D}_{\text {médio }}$ obtido.

\subsection{Análise metalográfica e MEV}

Todas as capas testadas apresentaram a formação de latão e crateras na superfície que entrou em contato com a chapa galvanizada durante a soldagem. Na figura 11a é mostrada a seção transversal da capa $\mathrm{D}$, após a execução de 1100 pontos de solda, onde percebe-se nitidamente a formação de duas crateras. Uma maior ampliação da região da borda da cratera, mostrada na figura $11 \mathrm{~b}$, evidencia que a superfície da capa está recoberta por camadas de diferentes características. Diretamente sobre o material da capa há uma camada amarelada (Região 3), seguida de uma camada acinzentada (Região 2). Por fim, dentro da cratera, há um material de coloração marrom (Região 1), que aparentemente ficou aprisionado nesta posição. A capa propriamente dita foi identificada como Região 4.

A análise destas regiões foi realizada através de EDS em MEV, e os resultados podem ser vistos na figura 12 e na tabela 2. A região 1 é a região da cratera que possui um material aprisionado, contendo uma grande concentração de $\mathrm{Zn}$, e em menor concentração aparecem $\mathrm{Fe}, \mathrm{Cu}$ o O.Esta composição mostra que esta região aprisiona principalmente o $\mathrm{Zn}$ do revestimento, que tende a expelido durante a soldagem.

Na região 2, a concentração de $\mathrm{Zn}$ ainda é alta, porém há uma diminuição na concentração de Fe e um aumento na concentração de $\mathrm{Cu}$. Não se trata mais de um material aprisionado, mas sim
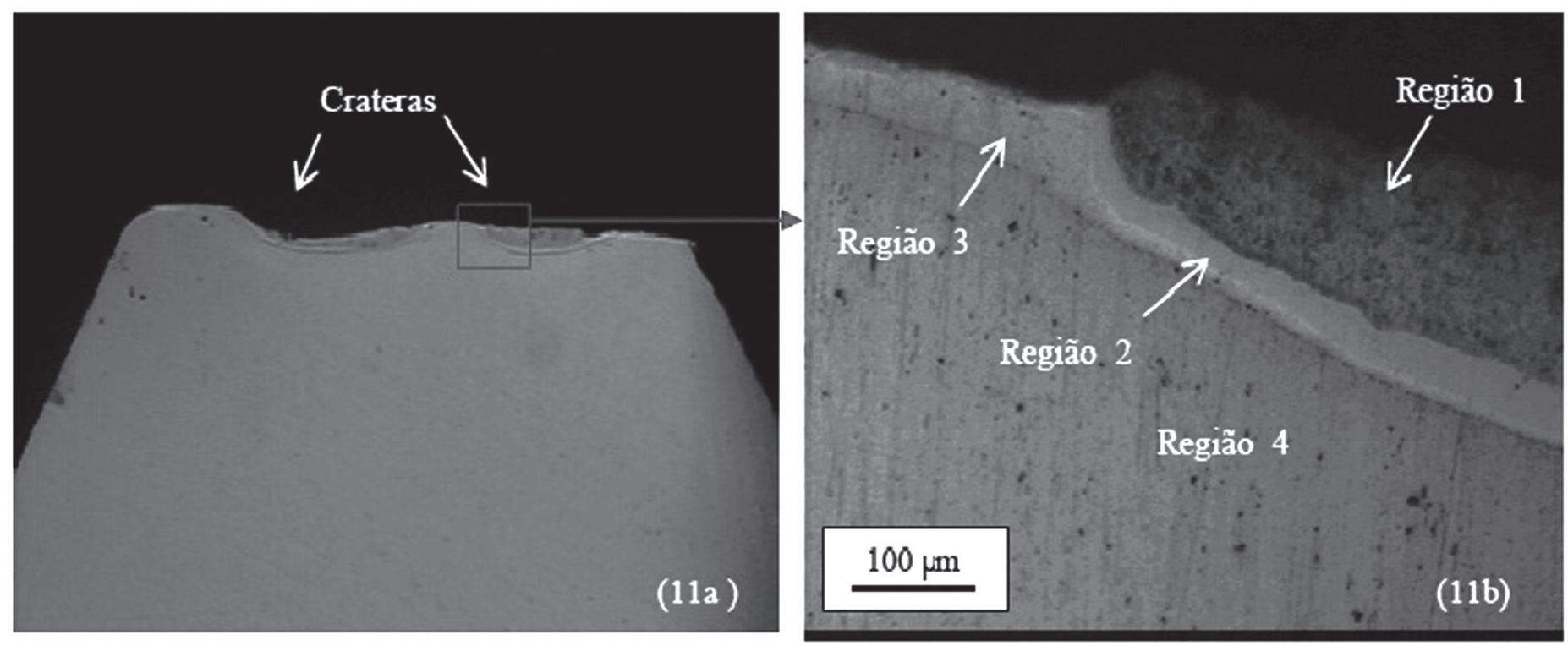

Figura 11. Metalografia da face das capas D após a soldagem de 1100 pontos de solda. 
de uma fase ternária $\mathrm{Zn}-\mathrm{Cu}-\mathrm{Fe}$, que se formou pela difusão dos átomos envolvidos.

A região 3 é composta basicamente por $\mathrm{Cu}$ e $\mathrm{Zn}$, formando uma camada de latão propriamente dita, apresentando inclusive a coloração correspondente. A espessura da camada de latão variou entre 10 a $50 \mu \mathrm{m}$, sendo esta espessura de 10 a $20 \mu \mathrm{m}$ na

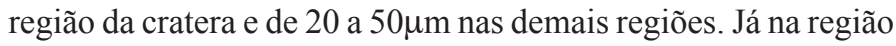
4 é a própria capa, e contem basicamente $\mathrm{Cu}$, como esperado.

Verifica-se, portanto, que ocorre intensa difusão na superfície da capa, o que gera formação de fases ternárias, latão e aprisionamento de material. Tais características afetam a resistividade nesta região, o que pode acarretar mudança no perfil de aquecimento por efeito joule, prejudicando a formação do ponto de solda. Estes resultados apresentam-se semelhantes aos obtidos por Guedes ET AL [7], o que certamente reduz a corrente de soldagem. Tal fato é mais um fator que favorece a redução do $\mathrm{D}_{\text {médio }}$, somando-se ao desgaste das capas.

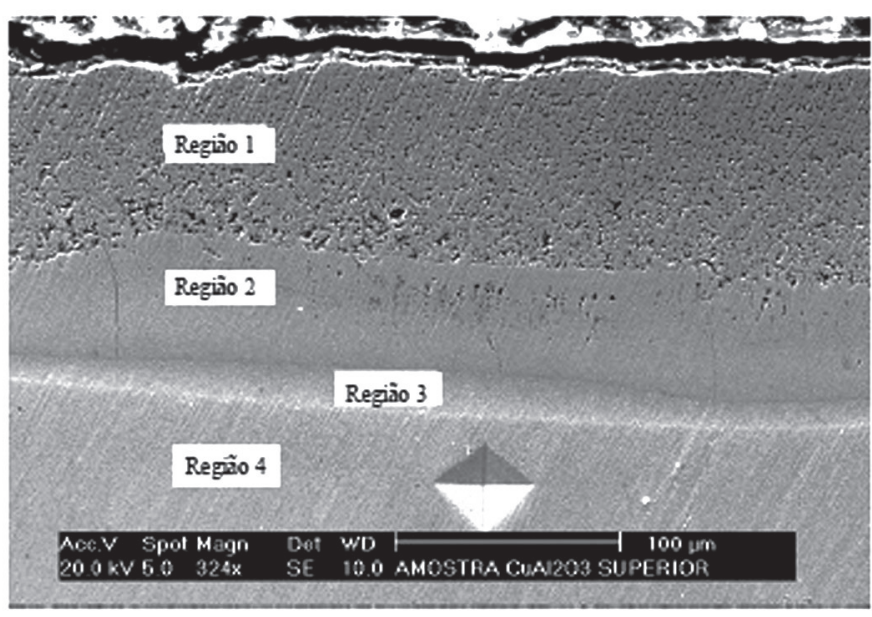

Figura 12. Foto em MEV da superfície da capa D após soldagem de 110 pontos de solda.

Tabela 2. Composição química em peso nas quatro regiões da capa D analisada por EDS.

\begin{tabular}{|l|c|c|c|c|}
\hline & $\mathrm{Cu}(\%)$ & $\mathrm{Zn}(\%)$ & $\mathrm{Fe}(\%)$ & $\mathrm{O}(\%)$ \\
\hline Região 1 & 5,24 & 83,07 & 10,04 & 1,65 \\
\hline Região 2 & 25,25 & 67,75 & 7,00 & -- \\
\hline Região 3 & 52,99 & 47,01 & -- & -- \\
\hline Região 4 & 100,00 & -- & -- & -- \\
\hline
\end{tabular}

\section{Conclusões}

Considerando os testes realizados com os 4 tipos de capas de eletrodos, utilizando os mesmos parâmetros de soldagem e espessuras de chapas galvanizadas, concluiu-se que :

- As capas de eletrodo são sujeitas a temperaturas na faixa de 800 a $900^{\circ} \mathrm{C}$ durante a execução dos pontos de solda, o que ocasiona uma redução substancial de sua dureza em relação ao estado como recebido;

- A redução de dureza observada favorece um processo de desgaste das capas de eletrodo durante a soldagem, que se manifesta por deformações plásticas, formação de crateras e uma camada contínua de latão na face das capas. Uma vez formadas, as crateras transferem seu formato para os pontos de solda na chapa galvanizada, piorando o seu acabamento;

- O desgaste observado nas 4 capas testadas ocorre de maneira diferenciada, tendo-se verificado que quanto maior a capacidade de retenção da dureza a quente da capa, menor é o desgaste resultante;

- A integridade estrutural do ponto de solda, medido pelo $\mathrm{D}_{\text {médio }}$, é diretamente afetado pelo desgaste das capas. Quanto maior o desgaste das capas, menor é o $\mathrm{D}_{\text {médio }}$ obtido;

- Em relação as 4 capas de eletrodo testadas, observou-se que as capas $\mathrm{D}\left(\mathrm{Cu}-\mathrm{Al}_{2} \mathrm{O}_{3}\right)$ e $\mathrm{C}(\mathrm{Cu}-\mathrm{Zr}$ - classe 1$)$ apresentaram os melhores resultados de soldagem quanto o número de pontos que estas capas conseguem soldar antes de atingirem um diâmetro mínimo do ponto de solda. O melhor desempenho da capa D deve-se a sua maior resistência ao desgaste, atribuído a capacidade de retenção de dureza a quente do endurecimento por dispersão realizado com partículas de $\mathrm{Al}_{2} \mathrm{O}_{3}$;

- O melhor resultado da capa $\mathrm{C}$ em relação a capa $\mathrm{A}$, que apresenta a mesma classe e liga, está associado a ausência do oxigênio durante o processo de fabricação, o que reduz significativamente o desgaste durante as soldagens executadas;

- Considerando que o desgaste das capas durante a soldagem é inevitável, deve-se considerar o processo de fresagem como uma etapa importante do processo de fabricação. Ao efetuar a fresagem, consegue-se manter a qualidade do ponto de solda e aumentar a produtividade das capas, pois recupera-se a geometria do perfil e faz-se uma limpeza da face das capas, retirando as crateras e a camada de latão formadas durante o processo de soldagem das chapas galvanizadas.

\section{Referências Bibliográficas}

[1] AGASHE, S.; ZHANG, H. Selection of schedules based on heat balance in Resistance Spot Welding, Welding Journal, USA, Jul. 2003, p. $179 \mathrm{~S}-183 \mathrm{~S}$.

[2] AWS - American Welding Society, Jefferson's Welding Enciclopedia. 18 ${ }^{\text {th }}$ Edition. Miami: 1997. p. 430,

[3] VOGLER, M.; SHEPPARD, S. Electrical contact resistance under high loads and elevated temperatures. Welding Journal, USA, June 2003.

[4] DONG, P.; KIMCHI, M. and Holmes, S. "Finite Element Modeling of Electrode Wear Mechanisms". Auto/Steel Partnership Technical Report No. AZ-017-03, April, 1995.

[5] INTERMACHINERY COMÉRCIO LTDA. I Seminário de Solda a Ponto. São Paulo: 2003, CD-ROM.

[6] YEUNG, K. S.; HORNTON, P. H. Transient Thermal Analysis of Spot Welding Electrodes. Welding Journal, Jan. 1999, p.1S - 6S.

[7] GUEDES, J.B.P., GONÇALVES , R.A. e SCOTTI. A., Avaliação de Desgaste de Eletrodos em Solda a Ponto por Resistência de Chapas Galvanizadas, In : XXX CONSOLDA - 
CONGRESSO NACIONAL DE SOLDAGEM, ABS, 13 a 15 de Setembro de 2004, Rio de Janeiro, RJ, 12 p.

[8] FUKUMOTO, S.; LUM, I.; BIRO, E.; BROMER, D. R.; ZHOU, Y. Effects of Electrode Degradation on Electrode Life in Resistance Spot Welding of Aluminum Alloy 5182. Welding Journal, USA, November 2003, p. 307S - 312S.

[9] MACHADO, I. Soldagem \& Técnicas Conexas: Processos. Porto Alegre: Ed. Pelo Autor, 1996.

[10] SCHARFF, R.; CARUSO, D. Complete Automotive Welding Metals and Plastic. New Yor : Delmar Publishers Inc., 1990.

[11] WAINER, Emílio, MELLO; Fábio D. H. de.; BRANDI, Sérgio Duarte. Soldagem Processos e Metalurgia. São Paulo: Editora Edgar Blücher, 1992.

[12] RWMA - Resistance Welder Manufacturers Association. Eletrodos e Ferramentas Utilizadas no Processo de Soldagem por Resistência Elétrica. 2002. p. 1 - 13.

[13] INTERMACHINERY COMÉRCIO LTDA. Manual de Treinamento do Z-Trode e Nitrode. 2002, 33p.

[14] VOLKSWAGEN AG. NORMA VW 01105-1: Winderstandspunktschweissen: Konstruktion, berechnung Prozesssicherung Umbeschichtete und beschichtete Stahlbleche. 2003.

[15] DONG, P.; KIMCHI, M. and HOLMES, S. „Finite Element Modeling of Electrode Wear Mechanisms". Auto/Steel Partnership Technical Report No. AZ-017-03, April, 1995. 